ENTREPRENEURSHIP AND SUSTAINABILITY ISSUES

ISSN 2345-0282 (online) http://jssidoi.org/jesi/

2020 Volume 7 Number 3 (March)

http://doi.org/10.9770/jesi.2020.7.3(12)

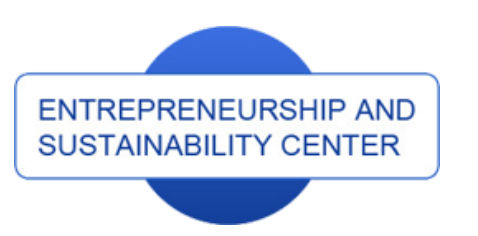

Publisher

http://jssidoi.org/esc/home

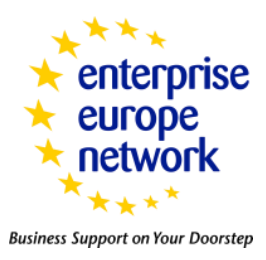

CASPA

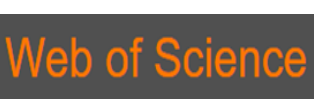

1 Clarivate

Analytics

\title{
ENSURING COMPETITION IN THE CONTEXT OF GLOBALIZATION OF MARITIME TRANSPORT SERVICES
}

\author{
Sergey G. Belyaev', Nikolay I. Dorogov², Ivan A. Kapitonov³ ${ }^{3}$, Svetlana N. Asabina ${ }^{4}$ \\ 1,2,4 Higher School of Tariff Regulation, Plekhanov Russian University of Economics, 117997, 36 Stremiannyy Lane, Moscow, \\ Russian Federation \\ ${ }^{3}$ Centre of Tariff Regulation in the Energy Sector, Plekhanov Russian University of Economics, 117997, 36 Stremiannyy \\ Lane, Moscow, Russian Federation \\ ${ }^{3}$ Department of Energy Policy, Institute of Economics of the Russian Academy of Sciences, 117218, 32 Nakhimovsky Ave., \\ Moscow, Russian Federation
}

\begin{abstract}
E-mails: ${ }^{1}$ serg.bel@kpi.com.de ; ${ }^{2}$ nik.dorogov@ubogazici.in; 3 i.kapitonov@national-univesity.info ;
${ }^{4}$ s.n.asabina@murdoch.in
\end{abstract}

Received 16 August 2019; accepted 17 January 2020; published 30March 2020

\begin{abstract}
Worldwide maritime shipping services are distinguished by the fact that this type of transportation is the lowest in cost and, as a consequence, the most common. This situation is identified by the fact that modern seaports can primarily serve not only as final delivery points, but also as regional hubs for other groups of goods. In this regard, competition measures are taken, which are tangent to tax revenues, seaports require greater attention to the taxation issue. The research is novel in that seaports become the basis for an international competitive situation. The authors determine that tax revenues depend not only on the geographical distribution of the port, but also on the international tax regime. In this regard, the use of specialized tax regimes, the time of their application and methods of termination require the establishment of individual tax regimes, which ports must develop and implement independently. The article develops a tax model applicable to a significant number of agents that are often in a state of cooperation. The practical application of the developed model can be presented to increase the investment attractiveness of the port in the structure of increasing the efficiency of the public sector of the economy.
\end{abstract}

Keywords: seaport; private investment; economic sovereignty; deregulation; tax model

Reference to this paper should be made as follows: Belyaev, S.G., Dorogov, N.I., Kapitonov, I.A., Asabina, S.N. 2020. Ensuring competition in the context of globalization of maritime transport services. Entrepreneurship and Sustainability Issues, 7(3), 1597-1611. https://doi.org/10.9770/jesi.2020.7.3(12)

JEL Classifications: F6, F21, L91, R41 


\section{Introduction}

In the context of the development of market relations in the Russian Federation, the globalization of economic relations, the deepening of the integration of the Russian economy into the world economic system, Russia's entry into the World Trade Organization, an important role is given to the steady growth of international cargo traffic.

Research of domestic and foreign scientists and relevant specialists indicates that the demand for transport services in the world on a whole grows annually by 6-8\% and significantly outruns the growth of world gross product. At the same time, most of the international cargo traffic are delivered by sea, facilitating over $80 \%$ of the total cargo traffic of world trade (Goloshchapova, 2018).

The main driver of the globalization of trade relations is the growth of the economy in the countries of the AsiaPacific region, which has had an active influence on the redistribution of major cargo flows between the regions.

The highest intensity of cargo traffic is observed between the countries of Europe, Asia-Pacific Region, and Russia. This tendency has led to an increase in commodity exchange and, as a consequence, to the volume growth of intercontinental cargo traffic. These factors indicate the key role of maritime transport in the development of the global economy and the implementation of international cargo transport.

\section{Literature Review}

For the efficient operation of the maritime shipping system, at least three conditions must be provided (Kemme, 2012):

1) the availability of modern ports with an integrated port infrastructure and the necessary number of hightech cargo ships (dry, liquid bulk, combined cargo) for shipping of various cargo, goods and materials from one port to another;

2) port industry deregulation;

3) development of interport competition.

In most economically developed countries, authorized state bodies do not consider themselves entitled to decide: whether it is expedient or not, from an economic standpoint, to build new ports or reorganize (modernize) existing port facilities (Brauers, 2013).

Decisions on these issues are taken solely at the initiative of the port authorities or private investors, who take responsibility for all risks arising at the stages of development, coordination and approval of the investment project, as well as during the construction and subsequent operation of the newly created (reconstructed, modernized) port infrastructure (Barros, 2005). Under these conditions, the main function of the state is, on the one hand, to ensure the "economic sovereignty" of ports, and, on the other hand, to create all the necessary conditions for inter-port competition, which facilitate (Rutter, 2018):

1) the attraction of private investment in the construction and reconstruction (modernization) of port infrastructure;

2) the improvement of port services;

3) the reduction of loading and unloading rates;

4) the reduction of cargo handling time.

At the same time, the "economic sovereignty" of ports acts as a powerful "stimulator" that encourages authorities and businesses to intensify their joint work on updating the current regulatory framework in the field of port development and the formation of a competitive environment (Haezendonck, 2000). 


\section{ENTREPRENEURSHIP AND SUSTAINABILITY ISSUES}

ISSN 2345-0282 (online) http://jssidoi.org/jesi/

2020 Volume 7 Number 3 (March)

http://doi.org/10.9770/jesi.2020.7.3(12)

The performed research of the competitive environment in the field of international maritime shipping allowed to establish that since the beginning of the 1980s, in many developed countries there has been a tendency to weaken state control in key industries and sectors of the economy, including in the provision of shipping services (Zauner, 2008).

The priority objectives of the governments of these countries were the establishment of a system of seaports as an independent market-oriented sector of international shipping, sensitive to the demand of consumers of services, and the development of inter-port competition (Haezendonck, 2000). At the same time, targeted privatization of seaports and the phasing out of state financing of their activities have become necessary conditions for adapting them to work in the maritime shipping market in the conditions of inter-port competition, improving management efficiency and quality, and improving the financial and economic results of their activities (Clément, 2014). For this, we should simulate tax revenues and identify a model that would allow sea ports to act as tax agents and provide a flexible tax policy in the context of globalization.

\section{Materials and Methods}

To build a multi-agent model according to the model structure and the concept of multi-agent modelling of the behaviour of economic agents in the conditions of tax competition, prototype models were developed to simulate individual processes and to build sustantial modules of the general model (Beresford, 2012).

The constructed prototype models are important as an independent tool for solving the issues of researching the behaviour of economic agents and tax competition (Burskyte, 2011). The prototype migration model is a discrete mathematical model of economic agent migration with a high level of aggregation (Veldman, 2003). As a mathematical apparatus, a one-dimensional discrete random walk of a particle is used, which was first applied to solve issues of mathematical finance (Ensslin, 2018). The basic assumption of the model is that the agent makes a decision on migration from the jurisdiction, proceeding from the current level of welfare (Van Der Horst, 2008).

The agent's welfare level is an aggregate indicator that characterizes its economic situation, to which such economic factors as, for example, the amount of its savings, consumption level, general living standards in the jurisdiction and satisfaction of the agent with jurisdiction, etc., contribute. (Flor, 2003). The model uses the assumption that factors affecting the agent's welfare are random (da Cruz, 2015).

\section{Results and Discussion}

Due to the fundamental nature, complexity and multiplicity of the essential facets of the economic category, which is generally referred to as the superconcept of "capital", over the centuries, scientific thought has been considering this issue, has already proposed and continues to create a significant number of definitions of the concept of "capital". It is noted that in the work of economists the essence of capital is manifested through its economic features, it can act as an "investment resource", "property object", "accumulated value", "production factor", "cost".

In the context of globalization processes, capital is mainly viewed through the lens of its economic nature as a financial or investment resource and factor of production. Indeed, in real economic activity, capital is the most diverse types of assets that can be represented by both physical capital, which directly takes part in the production process - constructions, machinery and equipment, vehicles, and financial capital, that circulates in various segments of global financial markets: stock, currency, insurance segment of derivative financial instruments, and the like. 
ENTREPRENEURSHIP AND SUSTAINABILITY ISSUES

ISSN 2345-0282 (online) http://jssidoi.org/jesi/

2020 Volume 7 Number 3 (March)

http://doi.org/10.9770/jesi.2020.7.3(12)

Thus, in order to generalize the existing variety of manifestations of the given economic category and to avoid overcomplicated detailing, this multi-agent model employs capital as the absolute cost of non-labour resources evaluated in monetary terms, which helps their owner to receive income, as well as agents that possess this type of resource - unemployed rentier.

In the context of globalization processes, the factor of labour production, its mobility and interstate competition for attracting this resource are mentioned as frequently as capital. Moreover, most often in the context of studying economic behaviour, it is a person whose mental and physical abilities are applied in production and constitute an economic resource for labour, and who makes economic decisions, is considered as a subject of research. To simulate the presence of the factor of labour production and simulate the behaviour of its owners, the corresponding type of economic agents - fundless workers - was introduced.

Other types of production resources, such as land, entrepreneurial abilities, and information in the framework of this multi-agent model are not allocated directly as production factors, with the help of which agents-owners can receive income, but they are indirectly implemented and described in other basic assumptions of the model. For example, the assumption of limited capacity of jurisdiction indirectly reflects the limited nature of such factors as land.

The subsequent assumption regarding the economic agents is that each agent receives income from a factor of production that it owns: owners of capital receive revenue; owners of labour receive wages. An agent who owns both labour and capital receives, respectively, both wages and revenue.

The amount of the agent's income depends on the return on the corresponding factor of production in the jurisdiction wherein it currently operates. This assumption regarding the multi-agent model was made on the basis of the economic theory of the reward of factors of production or reception of the factor income. Factor income is the income from a specific factor of production that the owner of a given production resource receives. In the real economy, there is a wide variety of types of income that owners of the production factor of capital can receive. Capital gains come in the form of dividends, retained earnings of companies, interest or part of self-employed income earned as income on equity.

Revenue is the income that the owner of the production resource of capital regularly receives from the use of property, land and other types of capital that are in its ownership. Obtaining this type of factor income does not require the owner of the factor of production to perform entrepreneurial activity or make mental or physical efforts.

If we refer to obtaining income from financial capital (which in its pure form is not a production factor, but can easily be converted into one), then the owner of this resource can receive different types of interest or dividends.

Since there is no separation of financial and real capital in the multi-agent model, and an absolutely estimated cost is taken as the appropriate resource for this type of agent, there is no separation of income from this type of production factor either.

The model makes the assumption that agents who possess labour as a factor in production receive income from using this factor. Indeed, in a real economy, where human efforts that are made physically or mentally in the production process to generate income are a factor of production - labour. And compensation to employees in exchange for their productive work is called wages. As previously noted, in this model, the agent's labour factor is taken as the absolutely estimated value of the agent as a labour resource, with consideration of the return on the labour factor in the jurisdiction of agent's operation, it receives a certain income, which depends on the amount of factor in its possession. 
The assumption that the factor incomes of the same agent differ in various jurisdictions is made as a consequence of the earlier assumption on the difference in returns from factors of production in various jurisdictions. Thus, in the real economy of different countries there is a different balance of particles of factor income, depending on what type of economic activity prevails in a given country. In countries where agriculture predominates, the highest is the share of factor income from the land factor. Countries with a low population and industrial production are characterized by a high share of factor income from capital exploitation. Thus, model jurisdictions, where the return on a particular factor is initially high, simulate one of the types of economic activity wherein the factor income from a given production resource predominates.

Agent's income is distributed between consumption and savings. Each agent regularly consumes part of the income received, while the volume of consumption is a random variable with the specified distribution parameters. The savings of the agent are formed per the residual principle after the consumption takes place. Savings form the personal state of agents and serves as an indicator of their welfare.

Also, savings can be used for consumption, if the income received by the agent was not enough for the desired level of consumption. This assumption was made with the purpose of realizing in the model of natural stocks for incomes received by agents, as well as for modelling the basic and most typical activities that almost all individuals perform in the course of their economic activity.

The variables of consumption and savings will be used in the future to describe and simulate mechanisms that model the satisfaction of an agent with its jurisdiction, as well as to model the agent's decision to change jurisdiction. Indeed, consumption is one of the basic economic categories, which is most often understood as the cost of products, goods, services, or other benefits that are used to meet the needs of the person engaged in consumption.

In the real economy, consumption is one of the links in the chain of reproduction process and is inextricably connected with its other stages - production, distribution and exchange. Moreover, the ultimate purpose of any production is consumption.

The random size of consumption at each model step is intended to simulate, on the one hand, all the random circumstances that make individuals in the real economy spend more or less, and on the other hand, to simulate such behavioural characteristics of economic agents as limited rationality and limited willpower.

Savings are a share of the agent's income that is not used for consumption at the moment when the agent received income and uses it, but is saved and can be used in the future for consumption, and, accordingly, to meet the needs of that period. The model does not consider the possibility of using savings for profit, such as, for example, obtaining interest from bank deposits or dividends from securities.

The model provides for several conditions under which the agent accumulates savings or, in other words, when its current income starts exceeding its current desired level of consumption. The agent accumulates savings either when its income level is large enough, which occurs if the agent has a relatively large number of production factors, as well as for a high level of return on this factor in a given period or a high level of provision of public goods that affect the return on this factor, in the jurisdiction where the economic agent is currently operating. Another condition under which the agent accumulates savings is the low desired current level of consumption, that is, the value of the random variable that models the consumption of the economic agent will be lower than the income received by the agent. Savings accumulated by the agent can be consumed if, at this model step, the agent received an income insufficient to realize the current desired consumption. 
ENTREPRENEURSHIP AND SUSTAINABILITY ISSUES

ISSN 2345-0282 (online) http://jssidoi.org/jesi/

2020 Volume 7 Number 3 (March)

http://doi.org/10.9770/jesi.2020.7.3(12)

The level of savings of an economic agent is one of the factors that affects the tendency of an agent to change jurisdiction. If the current savings of the agent are less than the savings in previous periods, then the tendency of the agent to migrate from this jurisdiction increases. This assumption is closely related to real observations, when individuals consider that they have sufficient income to maintain a certain level of savings that would guarantee them future consumption as an important indicator of economic welfare.

In the total set of taxes that exists in the global economy, each type of tax occupies a special place in the system to which it belongs, has its own purpose and distinctive features. In the theory of taxation, there are numerous classifications that organize the total set of taxes into specific groups according to a certain criterion. For example, you can classify taxes according to the subject of the payer (highlighting taxes from individuals, corporate taxes, mixed taxes, etc.), according to the object of taxation, according to the level of administrative bodies that appoint and tax them, etc. The most well-known is the tax classification proposed by the Organization for Economic Cooperation and Development, according to which there are six main groups: taxes on income, profit and capital gains, social security contributions, taxes on wages and labour, property taxes, taxes on goods and services, and other taxes.

To achieve the research objectives in the proposed multi-agent model, two types of taxes paid by economic agents are distinguished, which differ from each other in the type of tax base. Thus, a generalized tax on labour income appears in the model, which is accrued on the income of economic agents that own the labour factor; it acts as an analogue of taxes that are levied on individuals' income in the form of wages, remuneration, income from independent professional activity, and other income deriving from the use of an individual's mental or physical potential to receive remuneration.

The model also introduces a generalized conditional tax on capital income - a tax that should be levied on agents' income received on the factor resource capital. It is also a conditional, aggregate tax, which is a prototype of such real taxes as tax on investment income, income tax, tax on property income and taxes on other income received as a result of the exploitation of the production factor of capital by the subject.

To avoid overloading the model with additional relationships and blocks, was chosen the easiest way to calculate the amount that the agent must pay as taxes of the jurisdiction wherein it operates. It is defined as the income earned by the agent on a given model cycle from labour or capital, multiplied by the tax rate that is levied on income from the given factor in the given jurisdiction.

The behaviour of tax agents depends on the effectiveness of tax control. The model uses the assumption regarding the period of impact of the results of a tax audit on tax evasion by agents. It can be referred to as the "tax memory". Agents always pay taxes in full within a certain period when they are impressed by a successful tax audit on the part of the jurisdiction. Agents pay accrued taxes in full, but with a certain probability, if they are not under the impression of a tax audit anymore, that is, beyond the term of the "tax memory".

The tendency to evade taxes is, to a certain extent, inherent in every agent in the world. Subsequent to the verification of the economic agent by the jurisdiction regarding tax evasion and its discovery, the agent loses the tendency to evade taxes for a certain period. If the agent is satisfied with the terms of the jurisdiction, the tax evasion tendency decreases to a certain threshold value. The tendency of an economic agent to migrate is not related to a tax audit and increases if at some point in time the amount of savings becomes lower than the average value, and decreases if the amount of savings becomes higher than the average value.

The use of the proposed concept of modelling the behaviour of economic agents in the conditions of tax competition will facilitate the creation of a systematic idea of the behaviour of economic agents, the selection of a strategy in accordance with which a number of targeted measures can be determined. 
One of the manifestations of the behaviour of economic agents, namely the behaviour in the field of decisionmaking regarding taxation, is tax behaviour (Notteboom, 2001). The fundamental point in the study of tax behaviour is the determination of who exactly is the economic agent, and what a certain behaviour indicates (Potrykowski, 1986). The majority of domestic scholars points that the term "tax behaviour" is identical to the concept of taxpayer's behaviour. We shall consider this point of view in more detail.

In this paper, the tax behaviour of taxpayer agents shall be understood as an integral part of economic behaviour related to the payment of taxes, the agent's interaction with the outside world in this regard (Langen, 2004). The tax behaviour of an economic agent may include both certain actions and inaction regarding the performance of a tax obligation (Jeevan, 2019).

There are several approaches to the classification of tax behaviour of economic agents-taxpayers. The selfish behaviour of theoretical classification has three levels: opportunism, as the strongest manifestation of selfishness, simple observance of one's interests - an intermediate level, an indefinite form and a low level - full obedience (Min, 2017).

In turn, rationality also has three manifestations: maximization, limited rationality, and organic rationality. The first two manifestations of rationality - maximization and limited rationality - were described in a number of scientific sources. Organic rationality is a type of behaviour when a decision maker is guided in their actions by formal and informal rules of behaviour, rather than achieving a specific goal.

We shall suppose that the economic agent whose behaviour is simulated makes a decision on whether it will migrate from the jurisdiction wherein it acts at each point time $t=1,2, \ldots k$ according to the discrete model condition.

We shall describe the level of welfare at a point in time $t=n$ with the help of the variable $S(n)$, which can take only integer, integral values. We shall suppose that $S(n)$ changes according to the law:

$$
S(n+1)=\max \{0, S(n)+r(n)\}
$$

$r(1), r(2), \ldots r(n)_{-}$an increment of welfare, which depends on the results of the economic activity of the agent for the period from $n$ to $(n+1)$.

Consequently, the welfare increment is described using independent Bernoulli random variables. Welfare increment takes on two values: $r(k)=1$ with probability $\rho, r(k)=-1$ with probability $q=1-p$. Parameter $p$, a parameter that determines the probability of which particular sign is attributed to the increment. Being fixed in nature, it is not dependent on step $k$. In this formulation of the model, the parameter $p$ describes all the information about which particular sign the agent's increment is taking at a given moment, that is, it characterizes the entire economic life and environment of the agent.

We shall make the following assumption regarding the initial state of the economic welfare of the agent: we shall assume that at the zero time moment the level of welfare is positive, that is, $S(0)>0$. We shall also define a stop rule or, in other words, a rule that determines when the agent automatically makes a decision about migration. We 
believe that the agent migrates at the moment when at some step $n$ the level of welfare $S(n)$ becomes 0 . That is, the general level of welfare of the agent becomes zero.

We can set the probability that the agent migrates at a particular time $t=n$ using the function $p(n)$. We shall define $p(n)$ as the conditional probability that $S(n)=0$, provided that $S(1)>0, S(2)>0, \ldots, S(n-1)>0$.

Thus, the probability that the agent decides to migrate at a certain moment $n$ can be set as follows:

$$
p(n)=P(S(n)=0 \mid S(1)>0, S(2)>0, \ldots, S(n-1)>0) .
$$

The condition that the agent's welfare values are inherent in the previous steps is dictated by the assumption that it did not migrate in the previous steps, that is, the stop rule of the random process has not been performed so far. Considering existing assumptions, with the help of this model, the following aspects can be investigated in relation to the migration of an economic agent: it is possible to determine the likelihood that the agent at any given time decides to move to another jurisdiction throughout its entire economic life; it is possible to determine the expected (average) number of steps $M$ until the moment when the agent decides on migration.

We shall determine the probability that the agent will ever migrate $\left(p^{*}\right)$ through the presented $p(n)$ (probability of migration at a certain point in time $t=n$ ).

Values $\left(p^{*}\right)$ can be found by adding up all the $p(k)$.

$$
p^{*}=p(1)+p(2)+\ldots+p(k)+\ldots
$$

Since the event that the agent migrated at some point in time excludes that the agent migrated at any other time, the space of all possible results that the agent ever migrated can be divided into separate events of the following types: agent migrated at the first moment in time, at the second moment in time, and so on. These events are mutually exclusive, but if the migration event occurred at all, then it occurred at some of these points in time.

Therefore, in this case, the formula for total probability is applied, when the probability of a certain event is equal to the sum of the probabilities of events that do not intersect and together form this event.

The expected (average) number of steps $M$ until the moment when an agent decides to migrate takes the form:

$$
M=E(\min \{n \mid S(n)=0\})=1 p(1)+2 p(2)+\ldots+k p(k)+\ldots
$$

From a mathematical standpoint, the migration model described above represents the classical problem of asymmetric random walk on a half-line with an absorbing barrier. This problem allows a complete solution, which allows us to obtain explicit formulas for unknowns $p^{*}$ and $M$. When $p>0,5$, set problems have the following solution:

$$
p^{*}=p^{*}(k)=\left(\frac{q}{p}\right)^{k}
$$




$$
M=M(k)=\infty
$$

Thus, the agent with probability $1-p^{*}>0$ will forever stay in its jurisdiction. For the case when $p<0,5$, The solution to the above problems is as follows:

$$
\begin{gathered}
p^{*}=1 \\
M=M(k)=\frac{k}{(q-p)}
\end{gathered}
$$

An agent will almost certainly decide to migrate and migrates (on average) in $M(k)$ steps. In the case when $p=0,5$, the results will be as follows:

$$
\begin{gathered}
p^{*}=1 \\
M=\infty
\end{gathered}
$$

The mathematical expectation of the number of steps to migration tends to infinity. In other words, the agent does not migrate in a finite number of steps. This case is of particular interest from the standpoint of a substantial interpretation: it reflects the case when agents remain in the jurisdiction forever.

The model of savings of an economic agent - the savings and consumption of an economic agent is discrete: the agent receives income and carries out expenses at discrete points in time $t=1,2, \ldots n \ldots$ The current amount of the agent's savings after receiving income and carrying out expenses at a point in time $t=n$ we shall describe using the variable $S(n)$. We shall assume that at the point in time $t=n$ the agent spends a fixed share of its accumulations of the previous step $g(0<g<1)$, whichis not dependent on $n$, and which remained after the previous step $t=n-1$.

An agent can receive income from two factors - labour and capital. First, for simplicity, we shall consider a situation where the only income that an agent receives is income derived from the capital factor. A general view of the model can be obtained from this particular case.

Savings (or equity of the agent) remaining after consumption at a point in time $t=n-1$, which are equal to $(1-g) S(n-1)$ are invested by the agent. The agent invests this capital by distributing investments between a risk-free bank account and investments in production.

Thus, a fixed share of unused income $f(0<f<1)$ fits into the production factor with a random rate of return $d(n)$ - securities, investment assets, other risky investments, and its other share, which equals, respectively, $(1-f)$ placed in a bank account, which brings a fixed interest income at every step $h$. 
Proceeding from the given assumptions, the dynamics of savings $S(n)$ can be described by the equation:

$$
\begin{aligned}
& S(n)=(1-g)(1-f)(1+h) S(n-1)+(1-g) f d(n) S(n-1), \\
& n=1,2, \ldots
\end{aligned}
$$

Without loss of generality, this equation can be written as:

$$
S(n)=(a+r(n)) S(n-1)
$$

where $a=(1-g)(1-f)(1+h)$ _ constant, independent of $n$, a $r(n)=(1-g) f d(n)$ _ random amount of income received by the agent from an investment in a factor of production.

Here, parameter $\alpha$ contains aggregate information regarding all previously known and stable factors of agent expenses and income (including the share of fixed costs of available savings, interest income on deposits, etc.).

Since the equation described above is stochastic, that is, it has a random coefficient $r(n)$, it does not have a single solution in the classical sense. But we can describe the law of distribution of a random variable $S(n)$. Therefore, the task is to determine a probabilistic law that describes the distribution of a random process with discrete time and is determined by the equation (12).

By sequentially iterating equation (12) and shifting to the logarithmic form, we shall obtain:

$$
\ln \left(\frac{S(n)}{S(0)}\right)=\ln (a+r(1))+\ln (a+r(2))+\ldots+\ln (a+r(n))
$$

We shall further suppose that $r(1), r(2), \ldots-$ independent random variables distributed according to one law $R$, for which $\ln (\alpha+R)$ has finite first and second moments.

Such an assumption is made proceeding from the fact that although there are random factors, the nature of these random factors does not change. That is, the results may differ, but random factors that describe the functioning of this random economic environment wherein the agent operates are distributed according to the same law. In particular, this means that over time, new risk factors do not appear and those risk factors that already existed in the system do not disappear.

If $\mathrm{n}$ is big enough and if $r(n)$ has a finite second moment, then we can apply the central limit theorem to the sum on the right side of equation (2), which implies that the sum of the logarithms is distributed normally. And accordingly, what is under the logarithm $-\frac{S(n)}{S(0)}$ - shall be approximately described by a log-normal law. For clarity, we shall consider a particular case when $r(1), r(2), \ldots-$ Bernoulli random variables for which $r(k)=1$ with probability $p, r(k)=0$ with probability $q=1-p$. 
We shall also presume that $a>0$, which makes it possible to exclude the economically impossible case that savings will become negative. If we exclude the random coefficient $r(n)$ from the model, then upon $a>1$, the agent's savings increase exponentially, and if $a<1$ - the agent's savings decrease exponentially. With that $b(k)=\ln \left(1+\frac{r(k)}{\alpha}\right), k=1,2, \ldots$

is also a sequence of independent Bernoulli random variables with mathematical expectation $M=p \ln \left(1+\frac{1}{\alpha}\right)$ and dispersion $D=p q\left(\ln \left(1+\frac{1}{\alpha}\right)\right)^{2}$. We express the $\mathrm{b}(\mathrm{k})$ sum as follows:

$$
Z(n)=\frac{\left(\ln \left(\frac{S(n)}{S(0)}\right)-n \ln a\right)}{\ln \left(1+\frac{1}{a}\right)}
$$

It obeys the binomial law $B(n, p)$ with mathematical expectation $n p$ and dispersion $n p q$. Knowing the distribution $Z(n)$, we shall easily find the distribution of a random variable $S(n)$.

We shall consider the above equation for the dynamics of agent accumulation in a random economic environment

$$
S(n)=(\alpha+r(n)) S(n-1), n=1,2, \ldots
$$

where $\alpha$ - some constant independent of $\mathrm{n}$, and $r(n)$ - random variable (for example, net investment income per unit of invested capital).

We shall presume that $r(n)$ may take on values $b=f(1+k)$ with probability $p$ (favourable economic result) or value corresponding to adverse economic outcome $c=f(1+l<b)$ with probability $q=1-p$, that is, $r(n)$ is a generalized Bernoulli quantity.

It appears prudent to assume that the condition $\alpha+c>0$, which means that for any outcome, the agent's savings cannot be reset or negative (assuming that at the initial moment in time $S(0)>0$ ).

From an economic standpoint, the most interesting situation is when, at the same time, $\alpha+c<1$ and $\alpha+b>1$, that is, upon favourable outcome, the agent's savings increase: $S(n)>S(n-1)$, and upon unfavourable decrease: $S(n)<S(n-1)$.

Previously, a distribution was found $S(n)$ in a separate case, when $\alpha>0, b=1, c=0$. We shall display that the general case reduces to the previously obtained result.

We have $\ln \left(\frac{S(n)}{S(0)}\right)=\ln (\alpha+r(1))+\ln (\alpha+r(2))+\ldots+\ln (\alpha+r(n))$. For each $k=1,2, \ldots$ random variable 


$$
b(k)=\frac{(\ln (\alpha+r(k))-\ln (\alpha+c))}{(\ln (\alpha+b)-\ln (\alpha+c))}
$$

$b(k)$ takes on value of 1 with probability $p$ and 0 with probability $q$, i. e. with standard Bernoulli random variable.

With that, if random variables $r(1), r(2), \ldots$ are independent, then $b(1), b(2)$ are also independent. Thus, random variable

$$
Z(n)=\frac{\left(\ln \left(\frac{S(n)}{S(0)}\right)-n \ln (\alpha+c)\right)}{(\ln (\alpha+b)-\ln (\alpha+c))}=b(1)+b(2)+\ldots+b(n)
$$

obeys binomial law $B(n, p)$ with mathematical expectation $-n p$ and dispersion $-n p q$, whence we find distribution $S(n): S(n) C \exp [A B(n, p)]$, where

$$
\begin{aligned}
& C=S(0) \exp [n \ln (\alpha+c)] \\
& A=\ln (\alpha+b)-\ln (\alpha+c)
\end{aligned}
$$

We shall perform the initial parameterization of the developed model. Let us construct a scenario of the dynamics of savings of an economic agent close to a realistic one. For this, we shall examine the historical data for the stock market (S\&P 500 index). We shall write the equation of the average profitability for the period, as well as the average dispersion, which is found as the square of volatility. The average return was $10 \%$ and the standard deviation was $20 \%$. Thus, we have:

$$
\left\{\begin{array}{c}
p k+(1-p) l=0,10 \\
p(1-p)(k-l)^{2}=0,04
\end{array}\right.
$$

where $p$ is the probability of obtaining a positive economic result, $k$ is the size of the positive economic result, and 1 is a negative economic result.

Over 90 calendar years from 1928 to 2017, the index, per annual results, grew 66 times and dropped 24 times. Thus, it is possible to assess the probability of positive and negative economic results.

$$
\left\{\begin{array}{c}
p=\frac{66}{90}=0,73 \\
q=1-p=0,27
\end{array}\right.
$$


Substituting the values of $\mathrm{p}$ and $\mathrm{q}$ in (18), we shall obtain a system with two linear equations, by solving which we shall find the historical values of $\mathrm{k}$ and 1 . Thus, the positive economic result of the agent equals $k=0,2215$, and the negative result is $l=0,2285$.

We shall evaluate other model parameters. Thus, we shall take a fixed interest income $h$ as equal to $1 \%$, which corresponds to the average interest on deposits. We shall take the agent's cost level $g$ as equal to 4\%. And his risk appetite shall be medium, that is, the agent will prefer to invest $50 \%$ of its savings without risk, and the other $50 \%$ - in riskier but potentially more profitable areas.

Next, we shall perform a series of experiments that will allow to empirically study the dynamics of agent savings in various environmental conditions, as well as various types of agent behaviour and the nature of its consumption.

Let the initial capital of the agent be 10 conventional units. We shall perform 10 runs of the model with the parameters calculated above and for all runs we shall average the value of agent savings at each step.

In general, the simulated environment is characterized by a rather high probability of a positive economic result (73\%). Therefore, we shall also conduct a similar series of observations, reducing the probability of a positive economic result first to $50 \%$, in order to stimulate uniform negative and positive results. In the next step, the parameter $p$ was reduced in such a way as to simulate a situation where a negative economic result is more probable for an agent than a positive result for its economic activity $(p=0,4)$.

Let us study the obtained experimental results. With the parameters calculated on real data and in the case when $p=0,73$, the averaged accumulations of the agent demonstrate a growing trend during the observed 40 cycles of the model. The average value of savings is 11.97 conventional units.

For the second round of experiments, which simulated the activity of an agent with the same risk appetite and level of consumption as in the first round of the experiment, but with the probability of a positive economic result $p=0,5$. Proceeding from the experimental conditions, the agent is equally likely to get both negative and positive results, but in the long run, the dynamics of the agent's savings has a downward trend, and the average value of the indicator for the period is only 5.85 conventional units.

The third round of experiments was characterized by a greater probability of a negative economic result, and the probability of making a profit was only $p=0,4$. In this case, the savings of an economic agent are characterized by even more pronounced falling dynamics, and the average value for the period is 3.66 conventional units.

\section{Conclusions}

We studied the dynamics of the savings of an economic agent that owns the factors of capital and labour, with consideration of its consumption and its propensity for investment risk in a random economic environment. For this purpose, a mathematical model of discrete geometric random walk was applied. The model assumes that an agent can receive a fixed income from a labour factor and random (non-deterministic) income from a capital factor. Using the model, the distribution law of the random value of savings is obtained in explicit form.

With its help, the dynamics of the economic agent's savings was also researched under conditions similar to the real economic system (with more favourable conditions for risky investments), as well as in an environment with equally probable positive and negative results for the agent and in an unfavourable environment, with a more likely negative result. 
ENTREPRENEURSHIP AND SUSTAINABILITY ISSUES

ISSN 2345-0282 (online) http://jssidoi.org/jesi/

2020 Volume 7 Number 3 (March)

http://doi.org/10.9770/jesi.2020.7.3(12)

A multi-agent model of the economic agents' behaviour in the conditions of tax competition of jurisdictions can be applied in theoretical studies to obtain new knowledge regarding the impact of taxation on the behaviour of economic agents, the consequences of tax competition in jurisdictions; as well as in the analysis of applied issues of business entities for reasoning of decisions related to taxation, directions and tools of tax policy of jurisdictions of different levels.

The model allows multivariate calculations with variation of the values of economic and tax parameters and model variables to identify interdependencies and trends, and their quantitative assessment. Before commencing experiments with the model, it is necessary to perform an initial calibration of the general parameters of the model and the parameters of jurisdiction to achieve reasonable, from the standpoint of economic interpretation, values of the response variables upon subsequent model runs.

\section{References}

Barros, C.P. 2005. Decomposing growth in Portuguese seaports: a frontier cost approach, Maritime Economics \& Logistics 7(4): 297-315. https://doi.org/10.1057/palgra ve.mel.9100140

Beresford, A.; Pettit, S.; Xu, Q.; Williams, S. 2012. A study of dry port development in China, Maritime Economics \& Logistics 14(1): 7398. https://doi. org/10.1057/mel.2011.17

Brauers, W.K.M. 2013. Multi-objective seaport planning by MOORA decision making, Annals of Operations Research 206(1): 39-58. https://doi.org/10.1007/s10479-013-1314-7

Burskyte, V.; Belous, O.; Stasiskiene, Z. 2011. Sustainable development of deep-water seaport: the case of Lithuania, Environmental Science and Pollution Research 18(5): 716-726. https://doi.org/10.1007/s 11356-010-0415-y

Clément, B.; Guillen, B.; Xu, J.; Perrodin, Y. 2014. Ecotoxicological risk assessment of a quarry filling with seaport sediments using laboratory freshwater aquatic microcosms, Journal of Soils and Sediments 14(1): 183-195. https://doi.org/10.1007/s 11368-013-0782-3

da Cruz, M.R.P.; de Matos Ferreira, J.J. 2015. Evaluating Iberian seaport competitiveness using an alternative DEA approach, European Transport Research Review 8(1): 1. https://doi.org/10.1007/s12544-015-0187-z

Ensslin, L.; Dezem, V.; Dutra, A.; Ensslin, S.R.; Somensi, K. 2018. Seaport-performance tools: an analysis of the international literature, Maritime Economics \& Logistics 20(4): 587-602. https://doi.org/10.1057/s41278-017-0083-7

Flor, L.; Defilippi, E. (2003). Port infrastructure: an access model for the essential facility, Maritime Economics \& Logistics 5(2): 116-132. https://doi.org/10.1057/palgra ve.mel.9100075

Goloshchapova, L.V.; Plaskova, N.S.; Prodanova, N.A.; Yusupova, S.Y.; Pozdeeva, S.N. 2018. Analytical review of risks of loss of profits in cargo transportation, International Journal of Mechanical Engineering and Technology, 9(11): 1897-1902.

Haezendonck, E.; Coeck, C.; Verbeke, A. 2000. The competitive position of seaports: introduction of the value added concept, International Journal of Maritime Economics 2(2): 107-118. https://doi.org/10.1057/ijme.2000.10

Haezendonck, E.; Pison, G.; Rousseeuw, P.; Struyf, A.; Verbeke, A. 2000. The competitive advantage of seaports, International Journal of Maritime Economics 2(2): 69-82. https://doi. org/10.1057/ijme.2000.8

Jeevan, J.; Roso, V. 2019. Exploring seaport - dry ports dyadic integration to meet the increase in container vessels size, Journal of Shipping and Trade 4(1): 8. https://doi.org/10.1186/s41072-019-0047-4

Kemme, N. 2012. Effects of storage block layout and automated yard crane systems on the performance of seaport container terminals, $O R$ Spectrum 34(3): 563-591. https://doi.org/10.1007/s00291-011-0242-7 
ENTREPRENEURSHIP AND SUSTAINABILITY ISSUES

ISSN 2345-0282 (online) http://jssidoi.org/jesi/ 2020 Volume 7 Number 3 (March)

http://doi.org/10.9770/jesi.2020.7.3(12)

Langen, P. 2004. Governance in seaport clusters, Maritime Economics \& Logistics 6(2): 141-156. https://doi.org/10.1057/palgra ve.mel.9100100

Min, H.; Ahn, S.-B.; Lee, H.-S.; Park, H. 2017. An integrated terminal operating system for enhancing the efficiency of seaport terminal operators, Maritime Economics \& Logistics 19(3): 428-450. https://doi.org/10.1057/s41278-017-0069-5

Notteboom, T.E.; Winkelmans, W. 2001. Reassessing public sector involvement in European seaports, International Journal of Maritime Economics 3(2): 242-259. https://doi.org/10.1057/palgrave.ijme.9100008

Potrykowski, M.; Taylor, Z. 1986. Shipping policy and seaport development in Poland, GeoJournal 12(3): 281-288. https://doi.org/10.1007/BF00175014

Rutter, R.; Nadeau, J.; Lettice, F.; Lim, M.; Shamaisi, S. 2018. Place branding of seaports in the Middle East, Place Branding and Public Diplomacy 14(3): 197-212. https://doi.org/10.1057/s41254-017-0072-8

Van Der Horst, M.R.; De Langen, P.W. 2008. Coordination in hinterland transport chains: a major challenge for the seaport community, Maritime Economics \& Logistics 10(1): 108-129. https://doi.org/10.1057/palgrave.me1.9100194

Veldman, S.J.; Bückmann, E.H. 2003. A model on container port competition: an application for the west European container hub-ports, Maritime Economics \& Logistics 5(1): 3-22. https://doi.org/10.1057/palgrave.me1.9100058

Zauner, A. 2008. Strategic port planning: a case study of the Rotterdam seaport cluster applying the SWOT framework, Der Markt 47(3): 130-141. https://doi. org/10.1007/BF03159735

Sergey G. BELYAEV

ORCID ID: orcid.org/0000-0003-1039-5627

Nikolay I. DOROGOV

ORCID ID: orcid.org/0000-0002-3098-2741

Ivan A. KAPITONOV

ORCID ID: orcid.org/0000-0001-9713-4563

Sve tlana N. ASABINA

ORCID ID: orcid.org/0000-0002-2939-1311

Register for an ORCID ID:

https://orcid.org/re gister

Copyright (C) 2020 by author(s) and VsI Entrepreneurship and Sustainability Center

This work is licensed under the Creative Commons Attribution International License (CC BY).

http://creativecommons.org/licenses/by/4.0/

(c) (i) Open Access 